\title{
Management of Adverse Events Associated with Cabozantinib Treatment in Patients with Advanced Hepatocellular Carcinoma
}

\author{
Gabriel Schwartz ${ }^{1} \cdot$ Julianne O. Darling ${ }^{2} \cdot$ Malori Mindo $^{3} \cdot$ Lucia Damicis $^{4}$
}

Published online: 8 August 2020

(c) The Author(s) 2020

\begin{abstract}
Cabozantinib is an oral multikinase inhibitor whose targets include vascular endothelial growth factor receptors, MET, and the TAM family of kinases (TYRO3, AXL, MER). Cabozantinib is approved for patients with advanced hepatocellular carcinoma who have been previously treated with sorafenib, based on improved overall survival and progression-free survival relative to placebo in the phase III CELESTIAL study. During CELESTIAL, the most common adverse events (AEs) experienced by patients receiving cabozantinib included palmar-plantar erythrodysesthesia, fatigue, gastrointestinal-related events, and hypertension. These AEs can significantly impact treatment tolerability and patient quality of life. However, AEs can be effectively managed with supportive care and dose modifications. During CELESTIAL, more than half of the patients receiving cabozantinib required a dose reduction, while the rate of treatment discontinuation due to AEs was low. Here, we review the safety profile of cabozantinib and provide guidance on the prevention and management of the more common AEs, based on current evidence from the literature as well as our clinical experience. We consider the specific challenges faced by clinicians in treating this patient population and discuss factors that may affect exposure and tolerability to cabozantinib.
\end{abstract}

\section{Introduction}

There has been a marked increase in liver cancer deaths in recent years. In 2018, there were $~ 841,000$ new cases of liver cancer worldwide, and liver cancer accounted for almost 800,000 deaths, making it the sixth most prevalent cancer worldwide [1]. The most common primary malignancy of the liver is hepatocellular carcinoma (HCC) [2]. The frequency, burden, and etiology of HCC vary across geographic regions and populations but are linked to prevalence of predisposing chronic hepatic conditions such as

Electronic supplementary material The online version of this article (https://doi.org/10.1007/s11523-020-00736-8) contains supplementary material, which is available to authorized users.

Gabriel Schwartz

Gabriel.Schwartz@ucsf.edu

1 Gastrointestinal Medical Oncology Clinic, University of California San Francisco, 1825 Fourth St, Fourth Floor, San Francisco, CA 94158, USA

2 Indiana University Health Simon Cancer Center, Indianapolis, IN, USA

3 Department of Medicine, University of California San Francisco, San Francisco, CA, USA

4 IRCCS Istituto Clinico Humanitas, Rozzano, Milan, Italy

\section{Key Points}

Cabozantinib represents a treatment option for patients with advanced hepatocellular carcinoma who progress after sorafenib.

Adverse events associated with cabozantinib may be effectively managed with supportive care and dose modifications, thereby allowing patients to continue treatment at the appropriate dose, with minimum interruption.

Studies of cabozantinib in the first-line setting are ongoing; by understanding the safety profile of this drug, clinicians will be able to balance efficacy with tolerability for each patient.

viral hepatitis and nonalcoholic fatty liver disease (NAFLD) or nonalcoholic steatohepatitis (NASH), which generally develop in the setting of cirrhosis [3, 4]. In recent years, the incidence of nonviral HCC has increased while the proportion of HCC cases related to viral hepatitis has declined [3, 4]. Additional risk factors for HCC include alcohol consumption, smoking, obesity, and diabetes [2]. As the epidemiology of these conditions has evolved, so too has the etiology of HCC [2]. 
For patients with advanced HCC, the vascular endothelial growth factor receptor (VEGFR)-targeting tyrosine kinase inhibitor (TKI) sorafenib has been a standard of care [5]; however, the treatment landscape has been transformed in recent years with the introduction of newer TKIs, immunotherapies, and monoclonal antibody therapies [6]. This provides clinicians and patients with a variety of treatment options based on mechanism of action and safety profile.

Cabozantinib is a multikinase inhibitor that targets VEGFR 1-3, MET, the TAM family of kinases (TYRO-3, AXL, MER), RET, ROS1, KIT, TRKB, FLT-3, and TIE-2 $[7,8]$, several of which are implicated in tumor growth, angiogenesis, and immune regulation [8]. VEGFR, MET, and AXL have been implicated in the pathogenesis of HCC [9-11]. A capsule formulation of cabozantinib was first approved in 2012 for treatment of progressive, metastatic medullary thyroid carcinoma (MTC) [12]. The tablet formulation (not bioequivalent or interchangeable with the capsule [13]) was subsequently approved for patients with advanced renal cell carcinoma (RCC) $[14,15]$ and more recently for patients with advanced $\mathrm{HCC}$ who have received prior sorafenib [7, 16]. The approval in HCC was based on outcomes from the pivotal phase III CELESTIAL trial, which showed significantly improved overall survival (OS) and progression-free survival (PFS) with cabozantinib relative to placebo in patients who received prior sorafenib [17]. The safety profile of cabozantinib was manageable; nearly all patients receiving cabozantinib experienced an adverse event (AE), but these were effectively managed with dose modification and supportive care measures.

Clinicians treating patients with advanced $\mathrm{HCC}$ can face significant challenges, as many patients present with cirrhosis and co-morbidities that can impact treatment tolerability. Adequate assessment of liver function and management of co-morbidities are therefore essential before and during HCC treatment [18]. Here, we provide guidance on the management of AEs associated with cabozantinib in patients with advanced HCC. We briefly review outcomes from CELESTIAL and focus on managing some of the more common AEs experienced by patients, based on current evidence from the literature as well as our own clinical experience.

\section{Cabozantinib in Hepatocellular Carcinoma: CELESTIAL}

In the phase III CELESTIAL study, patients with advanced HCC were randomized 2:1 to treatment with cabozantinib $60 \mathrm{mg}$ daily or placebo [17]. Patients were required to have had prior treatment with sorafenib and could have received up to two prior systemic regimens for HCC. Eastern Cooperative Oncology Group (ECOG) performance status (PS) of 0 or 1 and Child-Pugh class A liver function (see Electronic
Supplementary Table 1 for definition) were also required. At the second planned interim analysis, 707 patients had been randomized. The study met its primary endpoint with significantly improved OS with cabozantinib relative to placebo; median OS was 10.2 versus 8.0 months (hazard ratio 0.76; $95 \%$ confidence interval $[\mathrm{CI}] 0.63-0.92 ; p=0.005)$. Cabozantinib also improved PFS, with a median of 5.2 versus 1.9 months (hazard ratio $0.44 ; 95 \%$ CI $0.36-0.52 ; p<0.001$ ), as well the objective response rate per Response Evaluation Criteria In Solid Tumors (RECIST) v1.1 (4\% vs. < 1\%; $p=0.009)$.

\subsection{Safety and Tolerability}

All-cause AE rates were generally higher in the cabozantinib arm than in the placebo arm; some of the more common AEs experienced by patients in the cabozantinib ( $>20 \%$ ) versus placebo arms included diarrhea (54\% vs. $19 \%$ ), decreased appetite ( $48 \%$ vs. $18 \%$ ), palmar-plantar erythrodysesthesia (PPE; $46 \%$ vs. $5 \%$ ), fatigue ( $45 \%$ vs. $30 \%$ ), nausea (31\% vs. $18 \%$ ), hypertension ( $29 \%$ vs. $6 \%$ ), vomiting ( $26 \%$ vs. $12 \%$ ), asthenia ( $22 \%$ vs. $8 \%$ ), and increased aspartate aminotransferase (AST; $22 \%$ vs. $11 \%$ ) (Fig. 1). The most common grade 3/4 AEs in the cabozantinib versus placebo arms were PPE ( $17 \%$ vs. $0 \%$ ), hypertension ( $16 \%$ vs. $2 \%$ ), increased AST ( $12 \%$ vs. $7 \%)$, fatigue ( $10 \%$ vs. $4 \%)$, and diarrhea (10\% vs. $2 \%$ ). Overall, the safety profile of cabozantinib was consistent with those from the phase III studies in RCC and MTC, with gastrointestinal (GI) events, PPE, fatigue, and hypertension being the most common AEs experienced by patients across studies [14, 17, 19].

In addition to supportive care measures, protocol-specified dose modification, including dose interruption and reduction, was utilized to manage AEs [17]. Eighty-four percent of patients in the cabozantinib arm had an AE that led to dose interruption, and $66 \%$ had a dose interruption due to a grade 3/4 AE [20]. Sixty-two percent of patients had at least one dose reduction due to an AE [17], and 38\% dose reduced due to a grade $3 / 4 \mathrm{AE}$ [20]. Thirty-three percent of patients had a second dose reduction [20]. Median time to first and second dose reduction in the cabozantinib arm was 38 days and 83 days, respectively. PPE was the event that most commonly led to dose interruption $(25 \%)$ and dose reduction $(22 \%)$, followed by diarrhea $(15 \%$ and $10 \%)$ and fatigue (13\% and 7.5\%) [20]. Although most patients receiving cabozantinib required a dose interruption, the rate of discontinuation due to treatment-related AEs was relatively low (16\% in the cabozantinib arm vs. $3 \%$ in the placebo arm), indicating that the majority of AEs were adequately managed with dose modification and supportive care. In the cabozantinib group, AEs that led to treatment discontinuation in $\geq 1 \%$ of patients were PPE, fatigue, decreased appetite, diarrhea, and nausea. In a subgroup analysis of patients 


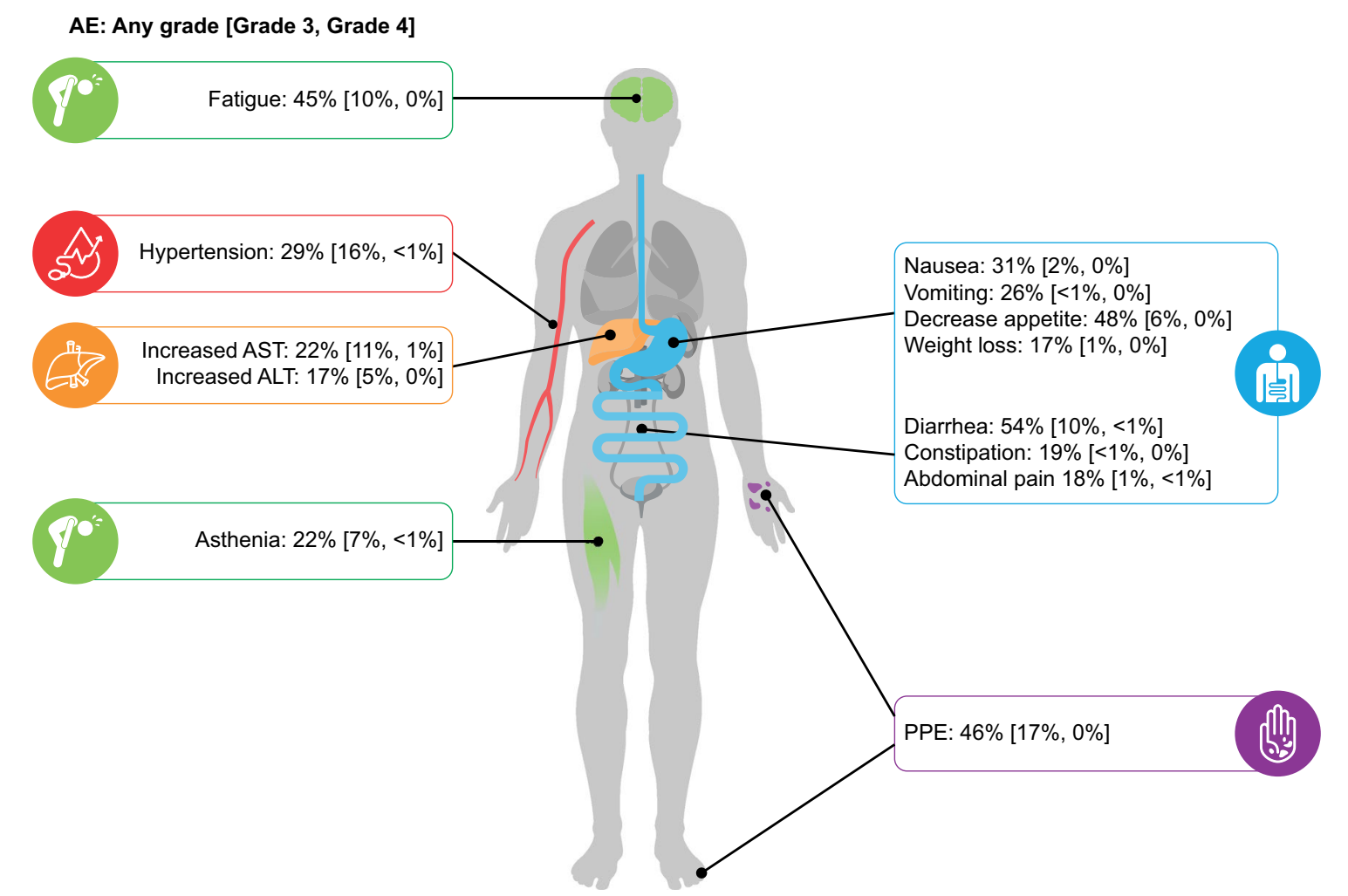

Fig. 1 Incidence rates for select AEs experienced by patients with HCC receiving cabozantinib during the CELESTIAL trial [17]. AEs are color coded by system: blue: gastrointestinal; purple: skin and subcutaneous tissue; green: constitutional; orange: hepatic disorders;

who received sorafenib as the only prior treatment for HCC, duration of prior sorafenib did not appear to impact the types or rates of grade $3 / 4$ AEs [21].

Generally, the more common AEs emerged in the first 6 weeks of treatment (Fig. 2). However, clinicians should be aware of infrequent or serious events that can occur in the later phases of treatment. Hemorrhagic events of grade 3 or higher were reported in $7.3 \%$ of patients in the cabozantinib arm, including five patients (1\%) with a grade 5 event. Bleeding complications are associated with antiangiogenic therapies and may arise as a result of reduced vascular integrity [22]. Median time to onset of hemorrhagic events was 9.1 weeks in CELESTIAL. Other grade 3 or higher rare but serious AEs in patients receiving cabozantinib included fistulas ( $0.6 \%$ of patients), GI perforations $(0.9 \%)$, and arterial (1.9\%) and venous or mixed thrombotic events (3.9\%) [20]. Median time to first occurrence was approximately 6 weeks for GI perforations, 9 weeks for venous and arterial thromboembolisms, and 14 weeks for fistulas [20]. Two patients in the cabozantinib arm (0.8\%) had developed Child-Pugh $\mathrm{C}$ (i.e., decompensated) cirrhosis by the week 8 assessment [20]. red: cardiovascular/hematological disorders. $A E$ adverse event, $A L T$ alanine aminotransferase, $A S T$ aspartate aminotransferase, $H C C$ hepatocellular carcinoma, $P P E$ palmar-plantar erythrodysesthesia

Reversible posterior leukoencephalopathy syndrome (RPLS), a syndrome of subcortical vasogenic edema diagnosed by magnetic resonance imaging, has been reported with cabozantinib and other TKIs [7, 23]. Although there were no RPLS events during CELESTIAL [20], clinicians should be aware of the symptoms, which include headaches, seizures, confusion, changes to vision, or altered mental function [7, 23]. Osteonecrosis of the jaw (ONJ), whereby necrotic jaw bone becomes exposed, is another rare but serious AE associated with TKIs including cabozantinib [24-26], although, again, there were no ONJ events reported during this study [20]. The use of antiresorptive drugs in patients with bone metastases is also associated with development of ONJ [27].

A post hoc analysis estimated the incremental qualityadjusted life-years accrued with cabozantinib compared with placebo, using the five-dimension five-level EuroQol questionnaire [28]. Cabozantinib treatment was associated with an initial decline in mean total quality-adjusted life-years during the first $2-3$ months relative to placebo, followed by long-term improvement that was significantly greater than that observed with placebo $(p<0.001)$. 
Fig. 2 Rates (\%) and timing of select AEs in patients with HCC receiving cabozantinib during the CELESTIAL trial. The size of the circle is proportional to the AE rate. AEs are color coded by system: blue: gastrointestinal; purple: skin and subcutaneous tissue; green: constitutional; orange: hepatic disorders; red: cardiovascular/ hematological disorders; black: general/other. $A E$ adverse event, $A T E$ arterial thrombotic event, $G I$ gastrointestinal, $G R$ grade, $H C C$ hepatocellular carcinoma, $P P E$ palmar-plantar erythrodysesthesia, VTE venous thrombotic event

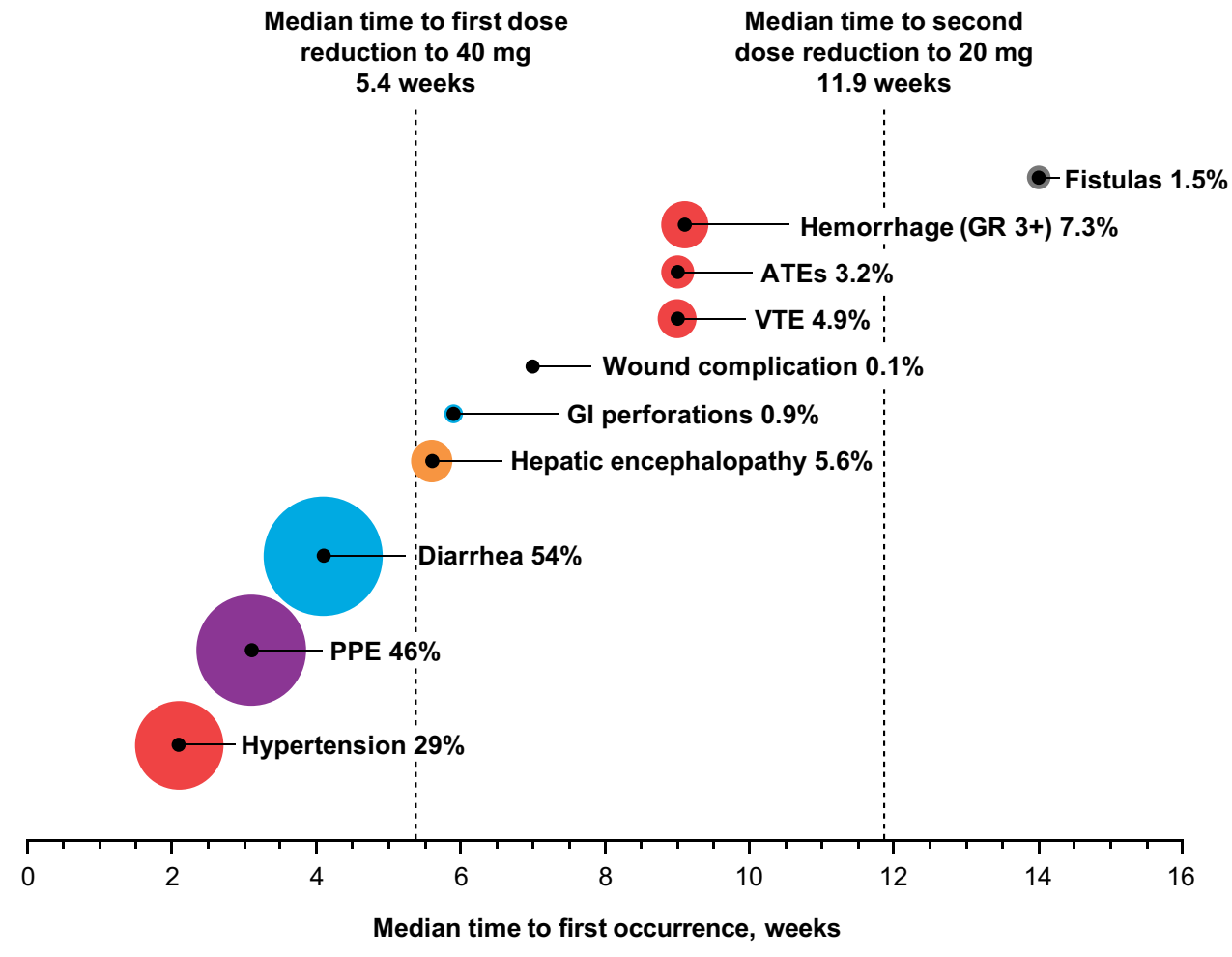

Median time to first dose ction to $40 \mathrm{mg}$

\section{Factors Affecting Tolerability of Cabozantinib}

\subsection{Co-morbidities}

HCC emerges primarily in older adults [29]. In addition to the underlying $\mathrm{HCC}$ etiology, older adults with $\mathrm{HCC}$ are likely to have additional co-morbidities such as cardiovascular or pulmonary disease [30], and it is not uncommon for patients with HCC to have multiple co-morbidities [31]. Liver cirrhosis, with compromised liver function and decreased hepatic reserve, is a major risk factor for HCC development. Other HCC-related co-morbidities include hepatitis $\mathrm{B}$ virus/hepatitis $\mathrm{C}$ virus infection, alcoholic liver disease, NASH, and diabetes [32]. In addition, metabolic syndrome, characterized by hyperlipidemia and hypertension, is linked to development of NAFLD, which may progress to NASH, cirrhosis, and finally HCC [33]. For patients with $\mathrm{HCC}$, assessment of liver function is a key step in treatment decision-making [5]. Patients with moderate or severe hepatic impairment are predominantly excluded from clinical trials in HCC; therefore, treatment of these patients is complicated by a lack of prospective clinical data as well as competing co-morbidities [6].

Although the number of patients with HCC and prior organ transplant is limited, these patients are generally excluded from clinical trials, and treatment is complicated by the need for immunosuppression. TKIs may be used to treat post-transplant $\mathrm{HCC}$ recurrence, although supporting data are limited. The use of TKIs in these patients is complex, so treatment decisions should involve collaboration between the oncology and transplant medicine care teams. The use of sorafenib in patients receiving mammalian target of rapamycin inhibitor-based immunosuppression has been associated with an increased risk of fatal bleeding $[34,35]$. Immunotherapies are associated with an increased risk of organ rejection in post-transplant patients [36].

\subsection{Cabozantinib Clearance and Exposure}

TKIs are associated with high interpatient variability in clearance and exposure, which may affect both efficacy and tolerability. This variability may be due to a variety of factors including genetic background, drug-drug interactions, drug-food interactions, and renal or hepatic impairment [37]. As evidenced by exposure-response modeling, patients with low clearance of cabozantinib may have higher exposure and an increased risk of developing certain AEs [38, 39]. Awareness of these nuances may help clinicians to mitigate their effects, thereby balancing efficacy with tolerability.

\subsection{Hepatic and Renal Impairment}

According to pharmacokinetic analyses of patients with $\mathrm{HCC}$ and other tumor types, mild hepatic impairment is predicted to have a minimal effect on cabozantinib exposure [40]; therefore, adjustment of the recommended 60-mg starting dose is not necessary for patients with Child-Pugh A 
liver function $[7,16]$. Data on the pharmacokinetics of cabozantinib in patients with moderate (Child-Pugh B) or severe (Child-Pugh C) hepatic impairment are limited [40]. As per the US Food and Drug Administration (FDA) prescribing information, the starting dose of cabozantinib should be reduced to $40 \mathrm{mg}$ in patients with moderate hepatic impairment, while cabozantinib is not recommended for patients with severe hepatic impairment [7]. Note that the European Summary of Product Characteristics (SmPC) does not recommend dose adjustments for moderate hepatic impairment owing to limited data [16]. For patients with HCC, increased exposure due to hepatic impairment should be considered if intolerable AEs develop, and dose modification undertaken as recommended (Fig. 3 [7, 16]). Cabozantinib should be used with caution in patients with mild or moderate renal impairment owing to the potential for increased exposure, although no dose adjustments are necessary. Cabozantinib is not recommended for use in patients with severe renal impairment owing to lack of data on safety and efficacy in this population $[7,16,41]$.

\subsection{Drug-Drug and Drug-Food Interactions}

Given the range of co-morbidities that may exist in patients with advanced HCC, it is important to review all concomitant medications for potential interactions prior to initiation of treatment with cabozantinib. Certain medications and foods have been shown to modulate the pharmacokinetics of cabozantinib, which may in turn impact exposure levels, efficacy, and risk of AEs. Cabozantinib is metabolized in the liver primarily by the enzyme cytochrome P450 3A4 (CYP3A4) [7]; therefore, CYP3A4 inhibitors or inducers may impact exposure (examples of CYP3A4 inducers/inhibitors are shown in Electronic Supplementary Table 2). Strong CYP3A4 inhibitors/inducers should be avoided in patients receiving cabozantinib. If concomitant administration of a strong CYP3A4 inhibitor is necessary, then the cabozantinib
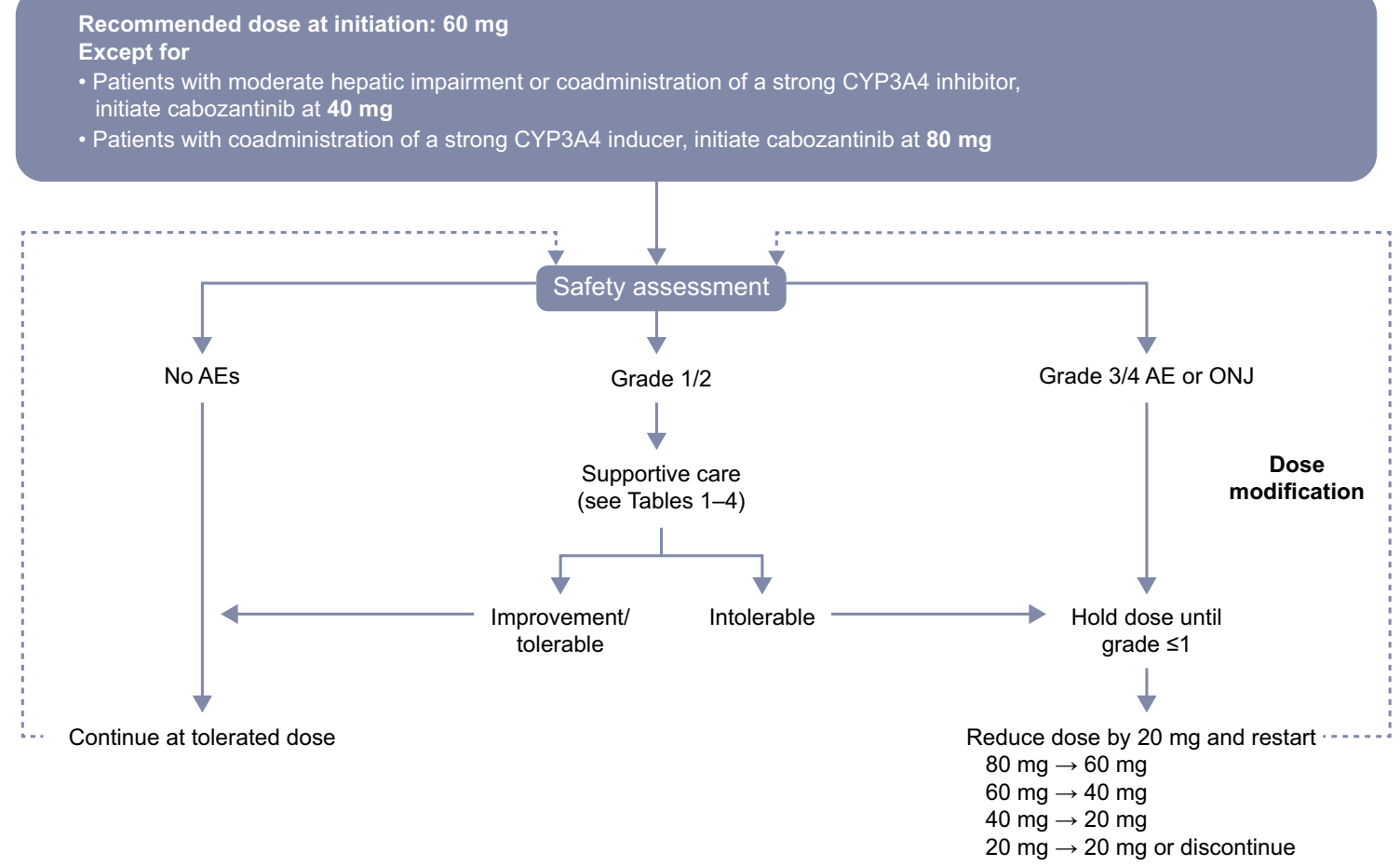

Immediate Discontinuation

- Severe hemorrhage

- Development of GI perforation or unmanageable fistula

- Serious thromboembolic event (eg, myocardial infarction, cerebral infarction)

- Hypertensive crisis or severe hypertension despite optimal medical management

- Nephrotic syndrome

- Reversible posterior leukoencephalopathy syndrome

Fig. 3 Cabozantinib dosing algorithm [7, 16]. AE adverse event, CYP3A4 cytochrome P450 3A4, GI gastrointestinal, ONJ osteonecrosis of the jaw 
dose should be reduced by $20 \mathrm{mg}$; for example, from 60 to $40 \mathrm{mg}$ [7]. Conversely, the cabozantinib dose should be increased by $20 \mathrm{mg}$ if strong CYP3A4 inducers need to be coadministered $[7,16]$.

Cabozantinib should not be taken with any food, as this may affect absorption [42]. The label recommends that cabozantinib be taken at least $1 \mathrm{~h}$ before or at least $2 \mathrm{~h}$ after eating [7]. Grapefruit and grapefruit juice are strong CYP3A4 inhibitors and should be avoided [7, 16].

Cabozantinib may be used with caution in patients who are receiving concurrent antiarrhythmics or other QT-prolonging agents [16]. This is based on a study of patients with MTC who received a daily 140-mg capsule dose of cabozantinib (recommended for this indication), in which the mean delta-delta QT interval was increased by approximately $10-15 \mathrm{~ms}$ with upper $95 \%$ CIs not exceeding 20 $\mathrm{ms}$ [43]. Such an increase is within the range considered to be acceptable for oncology drugs in this setting [44]. No patient in the aforementioned study or in CELESTIAL had a confirmed QTcF (QT corrected using Fridericia's method) $>500 \mathrm{~ms}$ [7], which is considered clinically significant [45]. For patients receiving cabozantinib, monitoring with periodic electrocardiogram and electrolyte measurements may be advisable, particularly in patients with risk factors such as cardiac disease or a prior history of QT prolongation [16]. Concomitant use of proton pump inhibitors (PPIs), such as esomeprazole, does not affect cabozantinib exposure levels [42]. However, PPIs may cause hypomagnesemia, which is linked to an increased risk of QT prolongation [46]. Therefore, coadministration of PPIs and cabozantinib should be undertaken with caution following an individualized assessment of the patient's baseline magnesium levels and concomitant medications that may also influence QT.

\section{Pretreatment Assessments}

Given the heterogeneity of the HCC patient population and the complexity associated with co-morbidities and concomitant medications, all patients should undergo a comprehensive assessment of medical history prior to initiation of treatment with cabozantinib. Ideally, the multidisciplinary care team should include an oncology pharmacist [47]. A "brown bag" medication review should be carried out prior to treatment initiation [48], whereby the patient brings in all current medications including over-the-counter medicines, vitamins, herbal remedies, etc. Therapeutic duplications should be eliminated, for example, concomitant PPIs and histamine $\mathrm{H} 2$ antagonists (H2 blockers). Switching and deprescribing should be considered where possible to minimize the risk of drug-drug interactions.

\section{Adverse Event Management}

The AE profile of cabozantinib is generally similar to that of other VEGFR-targeting TKIs, with GI-related AEs, fatigue, PPE, and hypertension being the most common AEs [17]. Other AEs that occur less frequently can also have a significant impact on quality of life (QoL) and treatment adherence, such as mucosal inflammation [49]. Hepatobiliary AEs such as elevated AST, alanine aminotransferase (ALT), and bilirubin are particularly relevant in the context of advanced HCC and need to be carefully monitored.

Prophylactic and supportive care measures for the more common cabozantinib-associated AEs (grade 1 or tolerable grade 2) are outlined in Tables 1, 2, 3, 4 and discussed in the upcoming sections. Symptom gradings are summarized in Electronic Supplementary Table 3. Dose interruption is recommended for management of intolerable grade 2 AEs not resolved with supportive care measures or for any grade 3/4 AEs (Fig. 3) [7, 16]. Cabozantinib may be reinitiated at a reduced dose once the event resolves to grade $\leq 1$.

\subsection{Palmar-Plantar Erythrodysesthesia}

PPE is one of the more common events associated with anticancer therapies including VEGFR-targeting multikinase inhibitors [50-52]. PPE is characterized by pain, redness, tingling, and swelling of hands and feet [53]. Presentation may vary according to the etiologic agent; PPE induced by TKIs is typically localized to pressure-bearing areas, in contrast to that caused by chemotherapy, which has a more diffuse pattern. It has been hypothesized that inhibition of multiple angiogenic pathways by TKIs may compromise repair of capillary microtrauma in areas exposed to mechanical stress, such as the hands and feet [50, 54]. Although not life-threatening, PPE can rapidly progress to a debilitating condition, negatively impacting QoL $[55,56]$.

Prophylaxis and prompt management of emerging symptoms may help to minimize the impact of PPE on QoL and adherence (Table 1). Prophylactic measures predominantly involve skin care practices to remove hyperkeratotic areas and to minimize friction and damage prior to the start of treatment [57, 58]. Recommendations include use of thick cotton gloves and socks, padded insoles in shoes, and avoidance of heat or friction on the hands and feet [57, 58]. Patients with potentially predisposing co-morbidities such as peripheral neuropathy $[59,60]$, as well as patients with persistent symptoms, may benefit from involvement of a podiatrist and/or dermatologist within their multidisciplinary care team [51]. Treatment strategies involve moisturization, prevention of infection, and analgesia [57, 61, 62]. Monitoring is crucial so that emerging symptoms can be proactively managed. Patients should be assessed at baseline 
Table 1 Adverse event management strategies-palmar-plantar erythrodysesthesia (PPE)

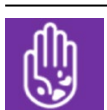

PPE

\section{Prophylaxis}

Provide education on prophylactic skin care before starting treatment [58]

Advise manicure and pedicure before and during treatment to remove hyperkeratotic areas $[57,61]$

Protect sensitive areas: recommend sunscreen with SPF protection $\geq 30$, thick cotton gloves and socks, padded insoles, and well-fitting shoes; avoid heat sources and use cooling aids, and avoid activities that may cause force or rubbing on the hands and feet (e.g., heavy lifting, dish washing) $[57,58,108]$; delegate such tasks to caregivers

Advise on optimal hand cleaning: avoid fragranced/foaming soaps and hand sanitizers containing alcohol; ensure hands are dried thoroughly after cleaning [63]

Prophylactically administer keratolytic cream (e.g., 10\% urea) [63, 109]

Monitor regularly in order to proactively manage skin toxicities: evaluate at baseline, monitor up to weekly for the first $2-4$ months and monthly thereafter $[63,64]$

\section{Supportive care}

Continue prophylactic measures [63]

Maintain moisture of skin using emollients [57, 61, 110]

Consider topical treatment with salicylic acid, urea $20-40 \%$ cream either alone or with tazarotene cream or 5\% fluorouracil cream, and/or clobetasol $0.05 \%$ cream; topical analgesics may be added for pain control [57, 61, 63]

Topical cortisone and clobetasol $0.05 \%$ may also be used; consider oral analgesics (e.g., NSAIDs, pregabalin, cautious use of opioids) [57, 61, 63]

Consult with a dermatologist to drain blisters and remove hyperkeratotic areas [63]

To prevent infection of cracked skin, soak in equal parts vinegar and water for 10 min per day [63]

Antibiotics should be prescribed only if there is evidence of infection [62]

There is limited evidence for the use of pyridoxine (vitamin B6) [111]

NSAID nonsteroidal anti-inflammatory drug, $S P F$ sun protection factor

Table 2 Adverse event management strategies-fatigue

\section{Fatigue}

\section{Prophylaxis}

Provide patient education about fatigue, management tools, and available support [72]

Establish baseline fatigue levels with a fatigue scale and remeasure regularly during patient visits [72]

Ensure adequate fluid and nutritional intake [72]

Advise behavioral modifications, balancing rest with physical activity; recommendations include relaxation, massage, yoga, aerobic or resistance exercise programs, and energy conservation strategies [67-71]

Assess thyroid function prior to treatment, and monitor during treatment $[66,112]$

\section{Supportive care}

Rule out alternative causes of fatigue (e.g., anemia, endocrine disorders such as hypothyroidism, pain, dehydration, hypercalcemia, or depression/anxiety) [67, 72]

Advise patient to increase activity; consider referral to a physical therapist [67]

Consider referral to nutritional counselor for nutritional therapy [67]

Incorporate psychosocial measures, including cognitive therapy, social support, biofeedback, and sleep therapy [67]

Incorporate management with psychostimulants (e.g., methylphenidate) [67, 73] or corticosteroids (e.g., methylprednisolone) [74]

Owing to effects on CYP3A4/5 substrates, including cabozantinib, long-term use of modafinil should be avoided [78]

CYP3A4 cytochrome P450 3A4, CYP2C19 cytochrome P450 2C19 
Table 3 Adverse event management strategies-gastrointestinal

\section{Gastrointestinal}

\section{Diarrhea}

\section{Prophylaxis}

Instruct patients to monitor food and fluid intake [113]

Recommended water intake per day (from all beverages and food) [114]: $2.7 \mathrm{~L}$ (91 oz) for women, $3.7 \mathrm{~L}$ (125 oz) for men

Advise patients to keep a stool diary and to promptly report diarrhea to their healthcare provider [63, 115]

Advise patients to avoid foods that may cause GI events such as lactose-containing foods, caffeine, high-fat or high-fiber food (e.g., nuts, seeds, legumes), and raw fruit and vegetables [83, 84]

Implement dehydration prevention management through oral rehydration with electrolytes [115]

\section{Supportive care}

Administer loperamide at the first sign of diarrhea [57, 115, 116]

$4 \mathrm{mg}$ orally followed by $2 \mathrm{mg}$ every $2 \mathrm{~h}$ until $2-24 \mathrm{~h}$ after last bowel movement (maximum of $16 \mathrm{mg}$ in $24 \mathrm{~h}$ )

For chronic diarrhea, 2-4 mg twice daily, titrated as needed

Alternatives to loperamide include diphenoxylate and tincture of opium [57]

Implement supportive dietary modifications (continuous oral hydration; correction of fluid and electrolytes; small, frequent meals; avoid lactosecontaining food and drink) [83, 84]

The BRAT (bananas, rice, applesauce, toast) diet may help to alleviate mild diarrhea [84]

If there are signs of severe dehydration, administer IV fluid replacement (isotonic saline or balanced salt solution) [83]

Rule out non-treatment-related causes (e.g., infectious diarrhea) [83]

\section{Decreased appetite}

\section{Prophylaxis}

Advise patients to monitor their appetite and weight [63]

Encourage patients to consume high-protein, calorie-rich food; fruit and vegetables; nutritional supplements that they may snack on throughout the day $[63,81]$

Advise patients to pre-prepare and freeze nutritional, preferred food [81]

\section{Supportive care}

Treat underlying nausea [63]

Consider involving a dietitian, who may recommend scheduled eating times [117]

Recommend a high-calorie diet [63]

Provide dietary education alongside dietary modifications and/or nutritional/vitamin supplements [118]

Use a pharmacologic agent to stimulate appetite, such as a CB1 receptor agonist (dronabinol) [63, 119], systemic corticosteroid (methylprednisolone) $[74,118]$, progestin (megestrol acetate) $[63,118]$, or mirtazapine $[89,90]$

\section{Nausea/vomiting}

\section{Prophylaxis}

Assess risk factors for nausea/vomiting prior to treatment [120]

Metoclopramide may be administered prophylactically [87]

Advise patients to avoid foods that are overly sweet, greasy, fried, or spicy [81]

\section{Supportive care}

Antiemetic agents such as dopamine receptor antagonists (e.g., metoclopramide, prochlorperazine) or 5-HT3 receptor agonists (e.g., ondansetron) are recommended for management of nausea or vomiting [87, 88]

Certain NK-1 receptor agonists (e.g., aprepitant and netupitant) and dexamethasone are inducers, inhibitors, and/or substrates of CYP3A4 and thus could alter cabozantinib exposure [87, 88]; however, the potential for ondansetron to prolong the QT interval must also be considered [121]

There is moderate evidence for olanzapine, an antipsychotic drug that blocks multiple neurotransmitters, as an antiemetic in this setting [87] 
Table 3 (continued)

\section{Mucosal inflammation/stomatitis}

\section{Prophylaxis}

A comprehensive dental examination should be conducted prior to treatment to identify potential complications [85]

Mitigation of potential risk factors [85, 122]

Modification of ill-fitting dentures

Appropriate care for pre-existing dental problems such as caries, ulcers, etc.

Regular oral assessments should be conducted throughout treatment $[85,122]$

Educate patients on good oral hygiene and oral care protocols, including written instructions [122]

The oral cavity should be washed using saline-containing mouthwash up to four times daily, and dentures should be regularly cleaned [85]

Painful stimuli (e.g., smoking, alcohol, hot food/drink, sharp or spicy food) should be avoided [85, 123]

\section{Supportive care}

Treat pain with doxepin $0.5 \%$ mouthwash or viscous lidocaine $2 \%[85,124]$

Lactobacillus lozenges may be used to reduce inflammation [125]

Obtain bacterial/viral culture if oral infection is suspected and treat infection as clinically indicated [126]

5-HT3 5-hydroxytryptamine, CB1 cannabinoid, CYP3A4 cytochrome P450 3A4, GI gastrointestinal, IV intravenous, NK neurokinin

Table 4 Adverse event management strategies-hypertension

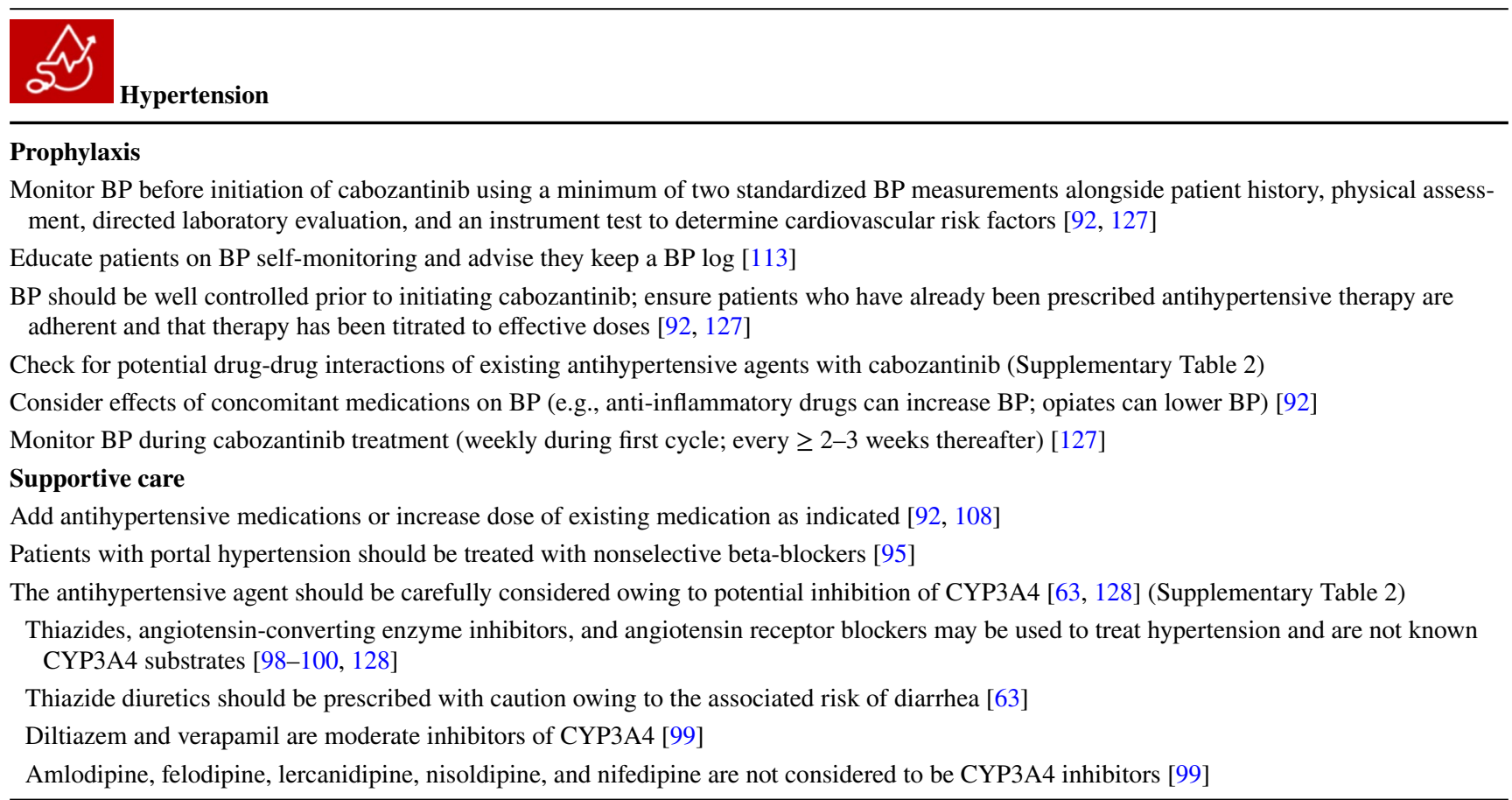

BP blood pressure, CYP3A4 cytochrome P450 3A4

and monitored at least weekly for the first 2-4 months of treatment, and monthly thereafter [63, 64]. Close monitoring in the early stages of treatment need not involve weekly visits-phone calls from a clinician, nurse, or pharmacist may facilitate monitoring in between scheduled appointments [65]. Patients should be encouraged to report early signs of PPE to their healthcare provider [58]; it may also be reassuring for patients to know that early reporting and management of AEs could help to reduce the risk of events progressing to a level that requires treatment interruption, dose reduction, or even discontinuation.

\subsection{Fatigue}

TKIs including cabozantinib are associated with fatigue, which may be a direct effect of the treatment or a consequence of other AEs such as myelosuppression, decreased appetite, diarrhea-induced dehydration, hypothyroidism, and 
hypophosphatemia $[63,66]$. Fatigue may also be a consequence of other treatments (e.g., radiation therapy) as well as sleep disturbance, anxiety, and depression [67]. Therefore, any strategy to manage treatment-related fatigue should first aim to assess and manage these predisposing factors.

There is mounting evidence that exercise may improve symptoms in patients suffering from cancer- or treatmentrelated fatigue $[68,69]$. Interventions should be tailored to the individual patient and may include light aerobic exercise and resistance training, short walks, or yoga [67-69] (Table 2). Energy conservation strategies have been shown to reduce fatigue in patients with cancer when used as part of a daily routine [70, 71]. Complementary interventions such as massage therapy and acupuncture have also shown preliminary efficacy and may be recommended to patients [67]. Patients should be educated about the importance of maintaining adequate hydration and nutritional intake for prevention of fatigue, and should be referred for nutrition counseling if necessary $[67,72]$.

Pharmaceutical strategies for the management of fatigue may also be considered. Studies have demonstrated the efficacy of psychostimulant medications such as methylphenidate and corticosteroids in treating cancer-related fatigue [73-75]. Although studies have indicated limited efficacy with modafinil $[76,77]$, modafinil is a CYP3A4 inducer that may reduce exposure to cabozantinib [78] and therefore should be avoided [7].

\subsection{Gastrointestinal Adverse Events}

VEGF is expressed in the GI tract and saliva and is important for mucosal homeostasis and repair within the GI tract $[22,79,80]$. Disturbance of the oral and GI mucosa as a consequence of inhibition of VEGF signaling may contribute to treatment-induced GI AEs [22]. Common GI AEs associated with cabozantinib include diarrhea, decreased appetite, nausea and vomiting, and mucosal inflammation [17]; prophylactic and supportive measures for management of these AEs are outlined in Table 3.

Prior to initiation of cabozantinib treatment, patients should be educated about adequate hydration and eating habits that may help to improve symptoms of GI-related AEs, such as regular snacking and small meals [81, 82]. Avoidance of specific foods can help to minimize the risk of diarrhea and nausea (e.g., high-fat, high-fiber, sweet, greasy, fried, or spicy foods) [83, 84], and the BRAT (bananas, rice, applesauce, toast) diet is recommended for the management of mild diarrhea [84]. To help mitigate mucosal inflammation and stomatitis, tobacco products, alcohol (including alcohol-containing mouthwash), and very spicy foods should be avoided, and rigorous dental hygiene should be maintained [85]. Patients should be asked about any planned dental surgeries or invasive dental treatment. Although rare, the risk of developing ONJ may necessitate withholding of cabozantinib if invasive dental procedures cannot be avoided, with treatment resuming once soft tissue has healed [86].

Following onset, GI symptoms may be managed pharmacologically, including loperamide for diarrhea [57, 63]. Antiemetic agents, such as ondansetron, prochlorperazine, or D2 dopamine receptor antagonists such as metoclopramide, may be administered at first signs of nausea or vomiting [87, 88]. For mucosal inflammation or stomatitis, viscous lidocaine or doxepin $0.5 \%$ mouthwash can be used to treat pain [85], although the latter is available only at compounding pharmacies. Effects of decreased appetite and weight loss may be mitigated by management of underlying symptoms such as nausea, but appetite stimulants such as mirtazapine could be considered $[89,90]$.

\subsection{Hypertension}

In patients treated with VEGFR-targeting TKIs, hypertension may be a consequence of VEGFR blockade-induced modulation of nitric oxide signaling, which is crucial for blood pressure (BP) control [91]. Providers should ensure that patients have adequate $\mathrm{BP}$ control prior to starting cabozantinib (Table 4). Pretreatment BP levels should be reviewed in the context of current medications; for example, nonsteroidal anti-inflammatory drugs can exacerbate hypertension [92]. During treatment, self-monitoring by patients may be helpful, particularly for those with an increased risk of cardiovascular events [93, 94]. If self-monitoring is prescribed, patients or caregivers should receive adequate training in the use of their BP device [94].

Portal hypertension is a major driver in the development of decompensated cirrhosis [95]. Nonselective betablockers are the mainstay of treatment for portal hypertension [95] and may reduce the risk of decompensation [96]. Patients with portal hypertension and HCC should continue to receive beta-blockers throughout $\mathrm{HCC}$ treatment unless they develop decompensated cirrhosis. Nonselective betablockers may be harmful in patients with decompensated liver cirrhosis (Child-Pugh C), and cabozantinib is not recommended in these patients [7, 16, 97, 98].

If an increase in BP is confirmed during cabozantinib treatment, the choice of antihypertensive agent should be carefully considered owing to potential inhibition of CYP3A4 by calcium channel blockers such as diltiazem and verapamil $[63,99]$. Angiotensin-converting enzyme inhibitors and angiotensin receptor blockers are not known CYP3A4 substrates and may be used to control hypertension $[63,92,99,100]$, although these drug classes should not be combined [100]. 


\subsection{Hepatobiliary Adverse Events}

Liver function abnormalities (increased levels of AST, ALT, and bilirubin) have been identified in patients treated with cabozantinib (Fig. 1) [17]. These AEs are particularly relevant in patients with HCC who may have compromised liver function. Laboratory tests for hepatic function should be performed prior to treatment and should be monitored closely during treatment; for example, every 2 weeks for the first 8 weeks, and every 4 weeks thereafter $[17,101,102]$. The CELESTIAL study protocol included guidelines for management of potential hepatobiliary disorders [17]. Elevations in AST or ALT may not require dose modifications if there are no progressive elevations (less than a doubling) in these enzymes or in serum total bilirubin or coagulation factors. Patients who have ALT, AST, and total bilirubin $\leq 3$ times $(X)$ the upper limit of normal (ULN) at baseline and who develop elevation of any of these at grade 3 or higher during cabozantinib treatment should have their treatment interrupted. If hepatic toxicity resolves during a temporary interruption, treatment may then be restarted at a reduced dose. Cabozantinib should be permanently discontinued when ALT or AST are elevated $>3 \times$ ULN with concurrent elevation of total bilirubin $>2 \times$ ULN or when hepatic dysfunction is not resolved after treatment interruption [17].

\subsection{Resources for Healthcare Professionals and Patients}

Patients should be directed to legitimate social media resources on the topics of $\mathrm{HCC}, \mathrm{AE}$ management, and $\mathrm{AE}$ reporting. Examples of resources for patients and caregivers are listed in Electronic Supplementary Table 4. Several mobile apps for patient symptom monitoring have been developed, but data on their effectiveness are limited [103]. Social media and online resources may provide positive support and practical advice for patients. However, patients should be made aware that not all sites are moderated by experts and, as such, may contain unreliable information [104]. Clinicians should consider tech literacy and patient preferences when recommending digital resources; certain patients may engage with online resources, apps, and text-based messaging, while others may prefer phone calls. Where possible, translated written educational materials should be provided for patients in their native language. A list of resources for oncology healthcare professionals caring for patients with $\mathrm{HCC}$ can be found in Table 5.
Case Study 1

Patient: A 67-year-old male patient with Child-Pugh A liver function and ECOG PS 1 with HCC who has progressed following 5 months on sorafenib as a first-line treatment. The patient has no underlying hepatitis but has NAFLD and type 2 diabetes. He also has hypertension with blood pressure (BP) of $145 / 92 \mathrm{mmHg}$, for which he is receiving a beta-blocker and calcium channel blocker (diltiazem). While receiving prior sorafenib treatment for HCC, the patient had his dose interrupted due to intolerable PPE.

$\rightarrow$ Cabozantinib was initiated at a dose of $60 \mathrm{mg}$.

AE management strategies prior to and during cabozantinib treatment

Manage hypertension by switching away from diltiazem, as it is a moderate inhibitor of CYP3A4

If the patient is willing to undertake self-assessment of BP at home, provide information on when and how to use the monitoring device

Discuss with the patient how to recognize common cabozantinibassociated AEs, strategies to help prevent these, and when to report them. Note that some of these AEs are similar to those experienced by patients receiving sorafenib

Emphasize strategies to reduce the risk or mitigate symptoms of PPE Treat any existing diabetes-related cutaneous conditions such as fungal infections, hyperkeratosis, or xerosis prior to starting cabozantinib

Refer the patient to a podiatrist or dermatologist if necessary

Schedule follow-up visits and allocate a team member to carry out follow-up phone calls between visits

\section{Case Study 2}

Patient: A 45-year-old Cantonese-speaking male patient with Child-Pugh B9 liver function and ECOG PS 0 has progressed following 5 months on nivolumab as a second-line treatment for HCC. The patient has a history of hepatitis B infection, which is now well controlled on entecavir, and mild chronic thrombocytopenia (platelet count $110 \times 10^{9} / \mathrm{L}$ ).

$\rightarrow$ Cabozantinib was initiated at a dose of $40 \mathrm{mg}$ owing to the moderate hepatic impairment.* While receiving cabozantinib treatment, the patient developed grade 2 PPE that was intolerable despite supportive care; cabozantinib dosing was interrupted until the PPE resolved to grade 1 or lower, and cabozantinib was restarted at a dose of $20 \mathrm{mg} /$ day.

Patient management strategies prior to and during cabozantinib treatment:

Low platelet count may indicate mild portal hypertension; carry out diagnostic tests such as endoscopy to screen for varices Collaborate with gastroenterology teams on periodic rescreening for varices

If diagnosed, treat portal hypertension with nonselective betablockers unless the patient should develop decompensated liver cirrhosis (Child-Pugh C)

Discuss with the patient how to recognize common cabozantinibassociated AEs, how to help prevent these, and when to report them Source written information in the patient's native language

Schedule follow-up visits and allocate a team member to carry out follow-up phone calls between visits

Carry out regular DNA testing to monitor for hepatitis B virus reactivation

Following development of intolerable grade 2 PPE:

Continue supportive care with topical treatment (see Table 1) and consider addition of oral analgesics

*Based on current US prescribing information for cabozantinib [7]; the EU SmPC for cabozantinib does not recommend dose adjustments for moderate hepatic impairment owing to limited data [16]. 
Table 5 Supportive care resources for management of AEs relevant to patients with HCC receiving cabozantinib

Resources for HCPs

\section{Oncology Nursing Society (ONS)}

Putting Evidence into Practice (PEP)

https://www.ons.org/the-pep-topics

Evidence-based interventions for patient care

$\begin{array}{ll}\text { Fatigue } & \text { Chemotherapy-induced nausea and vomiting } \\ \text { Depression } & \text { Mucositis } \\ \text { Anorexia } & \text { Skin reactions } \\ \text { Chemotherapy-induced diarrhea } & \end{array}$

National Comprehensive Cancer Network (NCCN)

Guidelines for supportive care https://www.nccn.org/professionals/physician_gls/default.aspx\#supportive

Evidence-based with consensus of expert panel

Cancer-related fatigue

Antiemesis

Distress management

Cancer Care Ontario

Managing symptoms, side effects, and well-being

https://www.cancercareontario.ca/en/symptom-management

Evidence-based with consensus of expert panel and external review

Anxiety
Depression
Exercise
Fatigue
Sleep disturbances
Constipation

\section{European Society of Medical Oncology (ESMO)}

ESMO clinical practice guidelines: Supportive and palliative care

https://www.esmo.org/Guidelines/Supportive-and-Palliative-Care

Evidence-based recommendations for the best standards of cancer care

Diagnosis, assessment, and management of constipation in advanced cancer

Diarrhea in adult cancer patients

Multinational Association of Supportive Care in Cancer (MASCC) and ESMO consensus guidelines for the prevention of chemotherapy- and radiotherapyinduced nausea and vomiting

Management of oral and gastrointestinal mucosal injury

Cardiovascular toxicity induced by chemotherapy, targeted agents, and radiotherapy

American Society of Clinical Oncology (ASCO)

Supportive care and treatment-related issues

https://www.asco.org/research-guidelines/quality-guidelines/guidelines/supportive-care-and-treatment-related-issues\%20

Systematic review of the medical literature by an expert panel

Antiemetics

Practical assessment and management of vulnerabilities in older patients receiving chemotherapy

Hematology/Oncology Pharmacy Association (HOPA)

Guidelines, standards, and summaries

http://www.hoparx.org/resources/guidelines-standards-summaries

Resources for pharmacists to optimize patient care, including summaries of HOPA-recommended resources, and evidence-based guidelines with consensus of expert panel

2018 HOPA best practices for the management of oral oncolytic therapy: Pharmacy practice standard

Oral chemotherapy resources

Multinational Association of Supportive Care in Cancer (MASCC)

MASCC guidelines

https://www.mascc.org/guidelines

Evidence-based with consensus of expert panel

MASCC/International Society of Oral Oncology (ISOO) clinical practice guidelines for the management of mucositis secondary to cancer therapy

MASCC/ESMO antiemetic guidelines

MASCC endothelial growth factor receptor (EGFR) inhibitor skin toxicity tool

ONS/Association of Community Cancer Centers (ACCC)/HOPA/National Community Oncology Dispensing Association (NCODA)

Oral Chemotherapy Education

www.oralchemoedsheets.com

Printable, patient-oriented information about oral chemotherapy drugs and side effects, reviewed and updated quarterly

AEs are color coded by system: gastrointestinal; skin and subcutaneous tissue; hematological disorders;

general/other

constitutional

hepatic disorders;

cardiovascular/

$A E$ adverse event, $H C C$ hepatocellular carcinoma, $H C P$ healthcare provider 


\section{Conclusions}

In the CELESTIAL study, cabozantinib demonstrated significant clinical benefit in patients with $\mathrm{HCC}$ who received prior sorafenib, showing improvements in disease control and survival relative to placebo. The study also highlighted the importance of strategic AE management and dose modification, as evidenced by the relatively low rate of discontinuation in the cabozantinib arm. Prior to initiating cabozantinib, patients and their caregivers should be educated on what adverse effects to expect, and when to notify their clinical team. Proactive preventative measures and prompt symptom management, as well as regular monitoring and follow-up should allow patients to continue treatment at the appropriate dose, with minimum interruption.

Preserving QoL is an important factor in treatment choice, particularly for patients with HCC whose well-being is further compromised by underlying liver disease. Data on the impact of TKIs on health-related QoL in patients with HCC are limited. Future randomized trials should aim to prospectively evaluate QoL in patients with $\mathrm{HCC}$ receiving systemic treatments, and to define optimal approaches that balance efficacy with tolerability.

Studies suggest that specific TKI-associated AEs may be correlated with treatment outcome [105, 106]; however, data on the prognostic significance of cabozantinib-related AEs are limited. An exploratory analysis of safety data in the CELESTIAL study showed that PPE of any grade and grade $3 / 4$ hypertension were independently associated with OS and PFS [107], highlighting the need for further research on this topic. There are a number of additional considerations for cabozantinib as the treatment landscape in HCC continues to evolve. With new frontline treatments available, including lenvatinib and the combination of atezolizumab plus bevacizumab, real-world and controlled clinical studies are needed to characterize the efficacy and safety of second-line cabozantinib following these agents. Further, the phase III COSMIC-312 trial (NCT03755791) will assess cabozantinib in combination with atezolizumab as a first-line treatment for patients with advanced HCC.

Acknowledgements Medical writing assistance was provided by Karen O'Leary, PhD, and Michael Raffin (Fishawack Communications Inc., Conshohocken, PA, USA), and was supported by Exelixis, Inc. (Alameda, CA, USA).

Author Contributions All authors contributed to the concept and drafting of the manuscript; all authors critically reviewed and approved the final submitted version.

Funding Medical writing assistance was provided by Karen O'Leary, $\mathrm{PhD}$, and Michael Raffin (Fishawack Communications Inc., Conshohocken, PA, USA) and was funded by Exelixis, Inc.
Code Availability Not applicable.

\section{Compliance with Ethical Standards}

Conflict of interest GS reports advisory board or speaker bureau fees from Exelixis, Eisai, and Amgen (all outside of the submitted work); JOD reports advisory board fees from Exelixis, Bayer, and Lilly (all outside of the submitted work); MM and LD have nothing to disclose.

Ethics approval Not applicable.

Open Access This article is licensed under a Creative Commons Attribution-NonCommercial 4.0 International License, which permits any non-commercial use, sharing, adaptation, distribution and reproduction in any medium or format, as long as you give appropriate credit to the original author(s) and the source, provide a link to the Creative Commons licence, and indicate if changes were made. The images or other third party material in this article are included in the article's Creative Commons licence, unless indicated otherwise in a credit line to the material. If material is not included in the article's Creative Commons licence and your intended use is not permitted by statutory regulation or exceeds the permitted use, you will need to obtain permission directly from the copyright holder. To view a copy of this licence, visit http://creativecommons.org/licenses/by-nc/4.0/.

\section{References}

1. International Agency for Research on Cancer. Cancer fact sheets: Liver 2019. http://gco.iarc.fr/today/data/factsheets/cancers/11Liver-fact-sheet.pdf. Accessed 03 Mar 2020.

2. Ghouri YA, Mian I, Rowe JH. Review of hepatocellular carcinoma: epidemiology, etiology, and carcinogenesis. J Carcinog. 2017;16:1. https://doi.org/10.4103/jcar.JCar_9_16.

3. Asrani SK, Devarbhavi H, Eaton J, Kamath PS. Burden of liver diseases in the world. J Hepatol. 2019;70(1):151-71. https://doi. org/10.1016/j.jhep.2018.09.014.

4. Goh GB, Li JW, Chang PE, Chow KY, Tan CK. Deciphering the epidemiology of hepatocellular carcinoma through the passage of time: a study of 1,401 patients across 3 decades. Hepatol Commun. 2017;1(6):564-71. https://doi.org/10.1002/hep4.1059.

5. Vogel A, Cervantes A, Chau I, Daniele B, Llovet J, Meyer T, et al. Hepatocellular carcinoma: ESMO Clinical Practice Guidelines for diagnosis, treatment and follow-up. Ann Oncol. 2018;29(Suppl 4):iv238-55. https://doi.org/10.1093/annonc/ mdy308.

6. Likhitsup A, Razumilava N, Parikh ND. Treatment for advanced hepatocellular carcinoma: current standard and the future. Clin Liver Dis (Hoboken). 2019;13(1):13-9. https://doi.org/10.1002/ cld.782.

7. Exelixis Inc. Cabometyx prescribing information. 2020. https:// cabometyx.com/downloads/CABOMETYXUSPI.pdf. Accessed 22 Feb 2020.

8. Yakes FM, Chen J, Tan J, Yamaguchi K, Shi Y, Yu P, et al. Cabozantinib (XL184), a novel MET and VEGFR2 inhibitor, simultaneously suppresses metastasis, angiogenesis, and tumor growth. Mol Cancer Ther. 2011;10(12):2298-308. https://doi. org/10.1158/1535-7163.mct-11-0264.

9. Bouattour M, Raymond E, Qin S, Cheng AL, Stammberger $\mathrm{U}$, Locatelli G, et al. Recent developments of c-Met as a therapeutic target in hepatocellular carcinoma. Hepatology. 2018;67(3):1132-49. https://doi.org/10.1002/hep.29496. 
10. Morse MA, Sun W, Kim R, He AR, Abada PB, Mynderse M, et al. The role of angiogenesis in hepatocellular carcinoma. Clin Cancer Res. 2019;25(3):912-20. https://doi.org/10.1158/10780432.CCR-18-1254.

11. Niu ZS, Niu XJ, Wang WH. Role of the receptor tyrosine kinase Axl in hepatocellular carcinoma and its clinical relevance. Future Oncol. 2019;15(6):653-62. https://doi.org/10.2217/ fon-2018-0528.

12. Exelixis Inc. Cometriq prescribing information. 2020. https:// www.cometriq.com/downloads/Cometriq_Full_Prescribing Information.pdf. Accessed 20 Mar 2020.

13. Nguyen L, Benrimoh N, Xie Y, Offman E, Lacy S. Pharmacokinetics of cabozantinib tablet and capsule formulations in healthy adults. Anticancer Drugs. 2016;27(7):669-78. https:// doi.org/10.1097/CAD.0000000000000366.

14. Choueiri TK, Escudier B, Powles T, Mainwaring PN, Rini BI, Donskov F, et al. Cabozantinib versus everolimus in advanced renal-cell carcinoma. N Engl J Med. 2015;373(19):1814-23. https://doi.org/10.1056/NEJMoa1510016.

15. Choueiri TK, Hessel C, Halabi S, Sanford B, Hahn O, Michaelson MD, et al. Progression-free survival by independent review and overall survival update for the Alliance A031203 CABOSUN trial of cabozantinib vs. sunitinib in metastatic renal cell carcinoma. Ann Oncol. 2017;28(Suppl 5):38.

16. Ipsen Pharma. Cabometyx $20 \mathrm{mg}$ Film-coated Tablets. Summary of product characteristics (SmPC). 2019. https://www.ema.europ a.eu/en/documents/product-information/cabometyx-epar-produ ct-information_en.pdf. Accessed 26 Feb 2020.

17. Abou-Alfa GK, Meyer T, Cheng AL, El-Khoueiry AB, Rimassa L, Ryoo BY, et al. Cabozantinib in patients with advanced and progressing hepatocellular carcinoma. N Engl J Med. 2018;379(1):54-63. https://doi.org/10.1056/NEJMoa1717002.

18. Pinter M, Trauner M, Peck-Radosavljevic M, Sieghart W. Cancer and liver cirrhosis: implications on prognosis and management. ESMO Open. 2016;1(2):e000042. https://doi.org/10.1136/esmoo pen-2016-000042.

19. Elisei R, Schlumberger MJ, Muller SP, Schoffski P, Brose MS, Shah $\mathrm{MH}$, et al. Cabozantinib in progressive medullary thyroid cancer. J Clin Oncol. 2013;31(29):3639-46. https://doi. org/10.1200/JCO.2012.48.4659.

20. European Medicines Agency. Assessment report: Cabozantinib. 2018. https://www.ema.europa.eu/en/medicines/human/EPAR/ cabometyx. Accessed 20 Mar 2020.

21. Kelley RK, Ryoo B-Y, Merle P, Park J-W, Bolondi L, Chan SL et al. Outcomes in patients who had received sorafenib as the only prior systemic therapy in the phase 3 CELESTIAL trial of cabozantinib versus placebo in advanced hepatocellular carcinoma. Abstract and poster presented at the ASCO Annual Meeting, June 1-5, 2018, Chicago.

22. Eskens FA, Verweij J. The clinical toxicity profile of vascular endothelial growth factor (VEGF) and vascular endothelial growth factor receptor (VEGFR) targeting angiogenesis inhibitors; a review. Eur J Cancer. 2006;42(18):3127-39. https://doi. org/10.1016/j.ejca.2006.09.015.

23. Shah RR. Anti-angiogenic tyrosine kinase inhibitors and reversible posterior leukoencephalopathy syndrome: could hypomagnesaemia be the trigger? Drug Saf. 2017;40(5):373-86. https:// doi.org/10.1007/s40264-017-0508-3.

24. Garuti F, Camelli V, Spinardi L, Bucci L, Trevisani F. Osteonecrosis of the jaw during sorafenib therapy for hepatocellular carcinoma. Tumori. 2016. https://doi.org/10.5301/tj.5000504.

25. Marino R, Orlandi F, Arecco F, Gandolfo S, Pentenero M. Osteonecrosis of the jaw in a patient receiving cabozantinib. Aust Dent J. 2015;60(4):528-31. https://doi.org/10.1111/adj.12254.

26. Mauceri R, Panzarella V, Morreale I, Campisi G. Medication-related osteonecrosis of the jaw in a cancer patient receiving lenvatinib. Int J Oral Maxillofac Surg. 2019. https:// doi.org/10.1016/j.ijom.2019.07.010.

27. Otto S, Pautke C, Van den Wyngaert T, Niepel D, Schiodt M. Medication-related osteonecrosis of the jaw: prevention, diagnosis and management in patients with cancer and bone metastases. Cancer Treat Rev. 2018;69:177-87. https://doi.org/10.1016/j. ctrv.2018.06.007.

28. Abou-Alfa GK, Mollon P, Meyer T, Cheng A-L, El-Khoueiry AB, Kelley RK et al. Quality-adjusted life years accrued with cabozantinib in patients with advanced hepatocellular carcinoma (aHCC) in the CELESTIAL trial. In: Abstract and poster presented at the 2019 ASCO Gastrointestinal Cancers Symposium, January 17-19, San Francisco, CA, USA.

29. Asahina Y, Tsuchiya K, Tamaki N, Hirayama I, Tanaka T, Sato $\mathrm{M}$, et al. Effect of aging on risk for hepatocellular carcinoma in chronic hepatitis C virus infection. Hepatology. 2010;52(2):518 27. https://doi.org/10.1002/hep.23691.

30. Brunot A, Le Sourd S, Pracht M, Edeline J. Hepatocellular carcinoma in elderly patients: challenges and solutions. J Hepatocell Carcinoma. 2016;3:9-18. https://doi.org/10.2147/JHC.S101448.

31. Hess LM, Cui ZL, Li XI, Wu Y, Girvan AC, Abada PB. Treatment patterns and costs of care for patients diagnosed with hepatocellular carcinoma (HCC) in the United States (U.S.). In: Abstract and poster (P-077) presented at the 2018 ESMO World Congress on Gastrointestinal Cancer, June 20-23, Barcelona, Spain.

32. Forner A, Reig M, Bruix J. Hepatocellular carcinoma. Lancet. 2018;391(10127):1301-14. https://doi.org/10.1016/S0140 -6736(18)30010-2.

33. Rahman R, Hammoud GM, Almashhrawi AA, Ahmed KT, Ibdah JA. Primary hepatocellular carcinoma and metabolic syndrome: an update. World J Gastrointest Oncol. 2013;5(9):186-94. https ://doi.org/10.4251/wjgo.v5.i9.186.

34. Mancuso A, Mazzola A, Cabibbo G, Perricone G, Enea M, Galvano A, et al. Survival of patients treated with sorafenib for hepatocellular carcinoma recurrence after liver transplantation: a systematic review and meta-analysis. Dig Liver Dis. 2015;47(4):324-30. https://doi.org/10.1016/j.dld.2015.01.001.

35. Toso C, Mentha G, Majno P. Integrating sorafenib into an algorithm for the management of post-transplant hepatocellular carcinoma recurrence. J Hepatol. 2013;59(1):3-5. https://doi. org/10.1016/j.jhep.2013.03.029.

36. Abdel-Wahab N, Safa H, Abudayyeh A, Johnson DH, Trinh VA, Zobniw CM, et al. Checkpoint inhibitor therapy for cancer in solid organ transplantation recipients: an institutional experience and a systematic review of the literature. J Immunother Cancer. 2019;7(1):106. https://doi.org/10.1186/s40425-019-0585-1.

37. Terada T, Noda S, Inui K. Management of dose variability and side effects for individualized cancer pharmacotherapy with tyrosine kinase inhibitors. Pharmacol Ther. 2015;152:125-34. https://doi.org/10.1016/j.pharmthera.2015.05.009.

38. Jonasch E, Motzer RJ, Escudier BJ, Powles T, Markby DW, Nielsen J et al. Cabozantinib exposure-response modeling of efficacy and safety endpoints as a function of clearance in patients with renal cell carcinoma. In: Presented at the ASCO 2018 Genitourinary Cancers Symposium, February 8-10, San Francisco, CA. 2018.

39. Nguyen L, Chapel S, Tran BD, Lacy S. Cabozantinib exposureresponse analyses of efficacy and safety in patients with advanced hepatocellular carcinoma. J Pharmacokinet Pharmacodyn. 2019;46(6):577-89. https://doi.org/10.1007/s10928-019-09659 $-\mathrm{y}$.

40. Nguyen L, Chapel S, Tran BD, Lacy S. Updated population pharmacokinetic model of cabozantinib integrating various cancer types including hepatocellular carcinoma. J Clin Pharmacol. 2019;59(11):1551-61. https://doi.org/10.1002/jcph.1467. 
41. Lacy SA, Miles DR, Nguyen LT. Clinical pharmacokinetics and pharmacodynamics of cabozantinib. Clin Pharmacokinet. 2017;56(5):477-91. https://doi.org/10.1007/s40262-016-0461-9.

42. Nguyen L, Holland J, Mamelok R, Laberge MK, Grenier J, Swearingen D, et al. Evaluation of the effect of food and gastric $\mathrm{pH}$ on the single-dose pharmacokinetics of cabozantinib in healthy adult subjects. J Clin Pharmacol. 2015;55(11):1293-302. https://doi.org/10.1002/jcph.526.

43. Miles DR, Lacy SA, Wada DR, Milwee S, Yaron Y, Nguyen LT. Assessment of cabozantinib treatment on QT interval in a phase 3 study in medullary thyroid cancer: evaluation of indirect QT effects mediated through treatment-induced changes in serum electrolytes. Cancer Chemother Pharmacol. 2017;80(2):295-306. https://doi.org/10.1007/s00280-017-3349-y.

44. Salvi V, Karnad DR, Panicker GK, Kothari S. Update on the evaluation of a new drug for effects on cardiac repolarization in humans: issues in early drug development. $\mathrm{Br}$ J Pharmacol. 2010;159(1):34-48. https://doi.org/10.111 1/j.1476-5381.2009.00427.x.

45. Drew BJ, Ackerman MJ, Funk M, Gibler WB, Kligfield P, Menon $\mathrm{V}$, et al. Prevention of torsade de pointes in hospital settings: a scientific statement from the American Heart Association and the American College of Cardiology Foundation. Circulation. 2010;121(8):1047-60. https://doi.org/10.1161/CIRCULATIO NAHA.109.192704.

46. Lazzerini PE, Bertolozzi I, Finizola F, Acampa M, Natale M, Vanni F, et al. Proton pump inhibitors and serum magnesium levels in patients with torsades de pointes. Front Pharmacol. 2018;9:363. https://doi.org/10.3389/fphar.2018.00363.

47. Mackler E, Segal EM, Muluneh B, Jeffers K, Carmichael J. 2018 Hematology/Oncology Pharmacist Association best practices for the management of oral oncolytic therapy: pharmacy practice standard. J Oncol Pract. 2019;15(4):e346-55. https:// doi.org/10.1200/JOP.18.00581.

48. Murtha E, Elder B, Faragher M. Brown bag medication review: using AHRQ's brown bag medication tool. J Nurs Care Qual. 2019. https://doi.org/10.1097/NCQ.0000000000000399.

49. Berger K, Schopohl D, Bollig A, Strobach D, Rieger C, Rublee $\mathrm{D}$, et al. Burden of oral mucositis: a systematic review and implications for future research. Oncol Res Treat. 2018;41(6):399405. https://doi.org/10.1159/000487085.

50. Lipworth AD, Robert C, Zhu AX. Hand-foot syndrome (handfoot skin reaction, palmar-plantar erythrodysesthesia): focus on sorafenib and sunitinib. Oncology. 2009;77(5):257-71. https:// doi.org/10.1159/000258880.

51. McLellan B, Ciardiello F, Lacouture ME, Segaert S, Van Cutsem E. Regorafenib-associated hand-foot skin reaction: practical advice on diagnosis, prevention, and management. Ann Oncol. 2015;26(10):2017-26. https://doi.org/10.1093/annonc/mdv244.

52. Bruix J, Qin S, Merle P, Granito A, Huang YH, Bodoky G, et al. Regorafenib for patients with hepatocellular carcinoma who progressed on sorafenib treatment (RESORCE): a randomised, double-blind, placebo-controlled, phase 3 trial. Lancet. 2017;389(10064):56-66. https://doi.org/10.1016/S0140 $-6736(16) 32453-9$.

53. Zuo RC, Apolo AB, DiGiovanna JJ, Parnes HL, Keen CM, Nanda S, et al. Cutaneous adverse effects associated with the tyrosine-kinase inhibitor cabozantinib. JAMA Dermatol. 2015;151(2):170-7. https://doi.org/10.1001/jamadermat ol.2014.2734.

54. Azad NS, Aragon-Ching JB, Dahut WL, Gutierrez M, Figg WD, Jain L, et al. Hand-foot skin reaction increases with cumulative sorafenib dose and with combination anti-vascular endothelial growth factor therapy. Clin Cancer Res. 2009;15(4):1411-6. https://doi.org/10.1158/1078-0432.CCR-08-1141.
55. Hackbarth M, Haas N, Fotopoulou C, Lichtenegger W, Sehouli J. Chemotherapy-induced dermatological toxicity: frequencies and impact on quality of life in women's cancers. Results of a prospective study. Support Care Cancer. 2008;16(3):267-73. https://doi.org/10.1007/s00520-007-0318-8.

56. Webster-Gandy JD, How C, Harrold K. Palmar-plantar erythrodysesthesia (PPE): a literature review with commentary on experience in a cancer centre. Eur J Oncol Nurs. 2007;11(3):238-46. https://doi.org/10.1016/j.ejon.2006.10.004.

57. Edmonds K, Hull D, Spencer-Shaw A, Koldenhof J, Chrysou M, Boers-Doets C, et al. Strategies for assessing and managing the adverse events of sorafenib and other targeted therapies in the treatment of renal cell and hepatocellular carcinoma: recommendations from a European nursing task group. Eur J Oncol Nurs. 2012;16(2):172-84. https://doi.org/10.1016/j.ejon.2011.05.001.

58. Dunne M, Liu C-M, Lacouture M. Skin and nail alterations. In: Brown CG, editor. A guide to oncology symptom management. Pittsburgh: Oncology Nursing Society; 2015.

59. Tanyi JL, Smith JA, Ramos L, Parker CL, Munsell MF, Wolf JK. Predisposing risk factors for palmar-plantar erythrodysesthesia when using liposomal doxorubicin to treat recurrent ovarian cancer. Gynecol Oncol. 2009;114(2):219-24. https://doi. org/10.1016/j.ygyno.2009.04.007.

60. Yokokawa T, Kawakami K, Mae Y, Sugita K, Watanabe H, Suzuki K, et al. Risk factors exacerbating hand-foot skin reaction induced by capecitabine plus oxaliplatin with or without bevacizumab therapy. Ann Pharmacother. 2015;49(10):1120-4. https://doi.org/10.1177/1060028015594451.

61. Anderson R, Jatoi A, Robert C, Wood LS, Keating KN, Lacouture ME. Search for evidence-based approaches for the prevention and palliation of hand-foot skin reaction (HFSR) caused by the multikinase inhibitors (MKIs). Oncologist. 2009;14(3):291302. https://doi.org/10.1634/theoncologist.2008-0237.

62. Grothey A, George S, van Cutsem E, Blay JY, Sobrero A, Demetri GD. Optimizing treatment outcomes with regorafenib: personalized dosing and other strategies to support patient care. Oncologist. 2014;19(6):669-80. https://doi.org/10.1634/theon cologist.2013-0059.

63. Rimassa L, Danesi R, Pressiani T, Merle P. Management of adverse events associated with tyrosine kinase inhibitors: improving outcomes for patients with hepatocellular carcinoma. Cancer Treat Rev. 2019;77:20-8. https://doi.org/10.1016/j. ctrv.2019.05.004.

64. De Wit M, Boers-Doets CB, Saettini A, Vermeersch K, de Juan CR, Ouwerkerk J, et al. Prevention and management of adverse events related to regorafenib. Support Care Cancer. 2014;22(3):837-46. https://doi.org/10.1007/s00520-013-2085-z.

65. BC Cancer. Symptom management guidelines: palmar-plantar erythrodysesthesia (PPE). 2019. http://www.bccancer.bc.ca/nursi ng-site/Documents/14.\%20Palmar\%20Plantar\%20Erythrodysest hesia.pdf. Accessed 16 Jan 2020.

66. Imel EA, Econs MJ. Approach to the hypophosphatemic patient. J Clin Endocrinol Metab. 2012;97(3):696-706. https://doi. org/10.1210/jc.2011-1319.

67. National Comprehensive Cancer Network. NCCN clinical practice guidelines in oncology: cancer-related fatigue. Version 1. 2019. https://www.nccn.org/professionals/physician_gls/defau 1t.aspx. Accessed 4 Mar 2020.

68. Kessels E, Husson O, van der Feltz-Cornelis CM. The effect of exercise on cancer-related fatigue in cancer survivors: a systematic review and meta-analysis. Neuropsychiatr Dis Treat. 2018;14:479-94. https://doi.org/10.2147/NDT.S150464.

69. Strasser B, Steindorf K, Wiskemann J, Ulrich CM. Impact of resistance training in cancer survivors: a meta-analysis. Med Sci Sports Exerc. 2013;45(11):2080-90. https://doi.org/10.1249/ MSS.0b013e31829a3b63. 
70. Barsevick AM, Dudley W, Beck S, Sweeney C, Whitmer K, Nail L. A randomized clinical trial of energy conservation for patients with cancer-related fatigue. Cancer. 2004;100(6):1302-10. https ://doi.org/10.1002/cncr.20111.

71. Sadeghi E, Gozali N, Moghaddam Tabrizi F. Effects of energy conservation strategies on cancer related fatigue and health promotion lifestyle in breast cancer survivors: a randomized control trial. Asian Pac J Cancer Prev. 2016;17(10):4783-90. https://doi. org/10.22034/apjcp.2016.17.10.4783.

72. Kollmannsberger C, Bjarnason G, Burnett P, Creel P, Davis M, Dawson N, et al. Sunitinib in metastatic renal cell carcinoma: recommendations for management of noncardiovascular toxicities. Oncologist. 2011;16(5):543-53. https://doi.org/10.1634/ theoncologist.2010-0263.

73. Gong S, Sheng P, Jin H, He H, Qi E, Chen W, et al. Effect of methylphenidate in patients with cancer-related fatigue: a systematic review and meta-analysis. PLoS One. 2014;9(1):e84391. https://doi.org/10.1371/journal.pone.0084391.

74. Paulsen O, Klepstad P, Rosland JH, Aass N, Albert E, Fayers $\mathrm{P}$, et al. Efficacy of methylprednisolone on pain, fatigue, and appetite loss in patients with advanced cancer using opioids: a randomized, placebo-controlled, double-blind trial. J Clin Oncol. 2014;32(29):3221-8. https://doi.org/10.1200/jco.2013.54.3926.

75. Tomlinson D, Robinson PD, Oberoi S, Cataudella D, CulosReed N, Davis H, et al. Pharmacologic interventions for fatigue in cancer and transplantation: a meta-analysis. Curr Oncol. 2018;25(2):e152-67. https://doi.org/10.3747/co.25.3883.

76. Conley CC, Kamen CS, Heckler CE, Janelsins MC, Morrow GR, Peppone LJ, et al. Modafinil moderates the relationship between cancer-related fatigue and depression in 541 patients receiving chemotherapy. J Clin Psychopharmacol. 2016;36(1):82-5. https ://doi.org/10.1097/JCP.0000000000000442.

77. Hovey E, de Souza P, Marx G, Parente P, Rapke T, Hill A, et al. Phase III, randomized, double-blind, placebo-controlled study of modafinil for fatigue in patients treated with docetaxel-based chemotherapy. Support Care Cancer. 2014;22(5):1233-42. https ://doi.org/10.1007/s00520-013-2076-0.

78. Cephalon Inc. Provigil prescribing information. 2004. https ://www.biopsychiatry.com/modafinil/modafinil-provigil.pdf. Accessed 08 Jan 2020.

79. Frysz-Naglak D, Fryc B, Klimacka-Nawrot E, Mazurek U, Suchecka W, Kajor M, et al. Expression, localization and systemic concentration of vascular endothelial growth factor (VEGF) and its receptors in patients with ulcerative colitis. Int Immunopharmacol. 2011;11(2):220-5. https://doi.org/10.1016/j. intimp.2010.11.023.

80. Keswani SG, Balaji S, Le LD, Leung A, Parvadia JK, Frischer $\mathrm{J}$, et al. Role of salivary vascular endothelial growth factor (VEGF) in palatal mucosal wound healing. Wound Repair Regen. 2013;21(4):554-62. https://doi.org/10.1111/wrr.12065.

81. American Cancer Society. Nutrition for the person with cancer during treatment. https://www.cancer.org/content/dam/CRC/ PDF/Public/6711.00.pdf. Accessed 26 Feb 2020.

82. American Cancer Society. Diarrhea. 2015. https://www.cance r.org/treatment/survivorship-during-and-after-treatment/stayi ng-active/nutrition/nutrition-during-treatment/diarrhea.html. Accessed 26 Feb 2020

83. Bossi P, Antonuzzo A, Cherny NI, Rosengarten O, Pernot S, Trippa F, et al. Diarrhoea in adult cancer patients: ESMO Clinical Practice Guidelines. Ann Oncol. 2018;29(Suppl 4):iv126-42. https://doi.org/10.1093/annonc/mdy145.

84. Thorpe DM, Byar KL. Bowel dysfunction. In: Brown CG, editor. A guide to oncology symptom management. Pittsburgh: Oncology Nursing Society; 2015.

85. Peterson DE, Boers-Doets CB, Bensadoun RJ, Herrstedt J. Management of oral and gastrointestinal mucosal injury: ESMO
Clinical Practice Guidelines for diagnosis, treatment, and follow-up. Ann Oncol. 2015;26(Suppl 5):v139-51. https://doi. org/10.1093/annonc/mdv202.

86. Di Fede O, Panzarella V, Mauceri R, Fusco V, Bedogni A, Lo Muzio L, et al. The dental management of patients at risk of medication-related osteonecrosis of the jaw: new paradigm of primary prevention. Biomed Res Int. 2018;2018:2684924. https ://doi.org/10.1155/2018/2684924.

87. Roila F, Molassiotis A, Herrstedt J, Aapro M, Gralla RJ, Bruera E, et al. 2016 MASCC and ESMO guideline update for the prevention of chemotherapy- and radiotherapy-induced nausea and vomiting and of nausea and vomiting in advanced cancer patients. Ann Oncol. 2016;27(Suppl 5):v119-33. https://doi. org/10.1093/annonc/mdw270.

88. National Comprehensive Cancer Network. NCCN clinical practice guidelines in oncology: antiemesis. 2019. https://www.nccn. org/professionals/physician_gls/default.aspx. Accessed 14 Jan 2020.

89. Riechelmann RP, Burman D, Tannock IF, Rodin G, Zimmermann C. Phase II trial of mirtazapine for cancer-related cachexia and anorexia. Am J Hosp Palliat Care. 2010;27(2):106-10. https:// doi.org/10.1177/1049909109345685.

90. Theobald DE, Kirsh KL, Holtsclaw E, Donaghy K, Passik SD. An open-label, crossover trial of mirtazapine $(15$ and $30 \mathrm{mg}$ ) in cancer patients with pain and other distressing symptoms. J Pain Symptom Manag. 2002;23(5):442-7.

91. Facemire CS, Nixon AB, Griffiths R, Hurwitz H, Coffman TM. Vascular endothelial growth factor receptor 2 controls blood pressure by regulating nitric oxide synthase expression. Hypertension. 2009;54(3):652-8. https://doi.org/10.1161/HYPER TENSIONAHA.109.129973.

92. Maitland ML, Bakris GL, Black HR, Chen HX, Durand JB, Elliott WJ, et al. Initial assessment, surveillance, and management of blood pressure in patients receiving vascular endothelial growth factor signaling pathway inhibitors. J Natl Cancer Inst. 2010;102(9):596-604. https://doi.org/10.1093/jnci/djq091.

93. McManus RJ, Mant J, Haque MS, Bray EP, Bryan S, Greenfield $\mathrm{SM}$, et al. Effect of self-monitoring and medication self-titration on systolic blood pressure in hypertensive patients at high risk of cardiovascular disease: the TASMIN-SR randomized clinical trial. JAMA. 2014;312(8):799-808. https://doi.org/10.1001/ jama.2014.10057.

94. Pickering TG, White WB, Giles TD, Black HR, Izzo JL, Materson BJ, et al. When and how to use self (home) and ambulatory blood pressure monitoring. J Am Soc Hypertens. 2010;4(2):5661. https://doi.org/10.1016/j.jash.2010.03.003.

95. Berzigotti A. Advances and challenges in cirrhosis and portal hypertension. BMC Med. 2017;15(1):200. https://doi. org/10.1186/s12916-017-0966-6.

96. Villanueva C, Albillos A, Genesca J, Garcia-Pagan JC, Calleja $\mathrm{JL}$, Aracil C, et al. beta blockers to prevent decompensation of cirrhosis in patients with clinically significant portal hypertension (PREDESCI): a randomised, double-blind, placebo-controlled, multicentre trial. Lancet. 2019;393(10181):1597-608. https://doi.org/10.1016/S0140-6736(18)31875-0.

97. Blasco-Algora S, Masegosa-Ataz J, Alonso S, Gutierrez ML, Fernandez-Rodriguez C. Non-selective beta-blockers in advanced cirrhosis: a critical review of the effects on overall survival and renal function. BMJ Open Gastroenterol. 2016;3(1):e000104. https://doi.org/10.1136/bmjgast-2016-000104.

98. Ge PS, Runyon BA. The changing role of beta-blocker therapy in patients with cirrhosis. J Hepatol. 2014;60(3):643-53. https ://doi.org/10.1016/j.jhep.2013.09.016.

99. Flockhart DA. Drug interactions: cytochrome P450 drug interaction table. Indiana University School of Medicine. 2007. https:// drug-interactions.medicine.iu.edu Accessed 31 Jan 2020. 
100. Whelton PK, Carey RM, Aronow WS, Casey DE Jr, Collins KJ, Dennison Himmelfarb C, et al. 2017 ACC/AHA/AAPA/ABC/ ACPM/AGS/APhA/ASH/ASPC/NMA/PCNA Guideline for the Prevention, Detection, Evaluation, and Management of High Blood Pressure in Adults: Executive Summary: A Report of the American College of Cardiology/American Heart Association Task Force on Clinical Practice Guidelines. Hypertension. 2018;71(6):1269-324. https://doi.org/10.1161/hyp.0000000000 000066.

101. Pace AF. Electrolyte imbalances, syndrome of inappropriate antidiuretic hormone, and tumor lysis syndrome. In: Brown C, editor. A guide to oncology symptom management. Pittsburgh: Oncology Nursing Society; 2015.

102. Klempner SJ, Choueiri TK, Yee E, Doyle LA, Schuppan D, Atkins MB. Severe pazopanib-induced hepatotoxicity: clinical and histologic course in two patients. J Clin Oncol. 2012;30(27):e264-8. https://doi.org/10.1200/JCO.2011.41.0332.

103. Warrington L, Absolom K, Conner M, Kellar I, Clayton B, Ayres $\mathrm{M}$, et al. Electronic systems for patients to report and manage side effects of cancer treatment: systematic review. J Med Internet Res. 2019;21(1):e10875. https://doi.org/10.2196/10875.

104. Prochaska JJ, Coughlin SS, Lyons EJ. Social media and mobile technology for cancer prevention and treatment. Am Soc Clin Oncol Educ Book. 2017;37:128-37. https://doi.org/10.14694/ EDBK_173841.

105. Granito A, Marinelli S, Negrini G, Menetti S, Benevento F, Bolondi L. Prognostic significance of adverse events in patients with hepatocellular carcinoma treated with sorafenib. Therap Adv Gastroenterol. 2016;9(2):240-9. https://doi. org/10.1177/1756283X15618129.

106. Liu Y, Zhou L, Chen Y, Liao B, Ye D, Wang K, et al. Hypertension as a prognostic factor in metastatic renal cell carcinoma treated with tyrosine kinase inhibitors: a systematic review and meta-analysis. BMC Urol. 2019;19(1):49. https://doi. org/10.1186/s12894-019-0481-5.

107. Abou-Alfa GK, Meyer T, Cheng A-L, Cicin I, Bolondi L, Klümpen H-J et al. Association of adverse events with efficacy outcomes for cabozantinib in patients with advanced hepatocellular carcinoma in the phase 3 CELESTIAL trial. In: Abstract and poster presented at the ASCO Annual Meeting, May 31-June 4, 2019, Chicago.

108. Exelixis Inc. Cabometyx ${ }^{\circledR}$ (cabozantinib) treatment management guide: strategies to manage adverse reactions and find the right dose as needed. 2019. https://cabometyxhcp.com/downloads/ CABOMETYX-TreatmentManagementGuide.pdf. Accessed 26 Feb 2020

109. Ren Z, Zhu K, Kang H, Lu M, Qu Z, Lu L, et al. Randomized controlled trial of the prophylactic effect of urea-based cream on sorafenib-associated hand-foot skin reactions in patients with advanced hepatocellular carcinoma. J Clin Oncol. 2015;33(8):894-900. https://doi.org/10.1200/jco.2013.52.9651.

110. Cancer.net. Hand-foot syndrome or palmar-plantar erythrodysesthesia. 2017. https://www.cancer.net/coping-with-cancer/physi cal-emotional-and-social-effects-cancer/managing-physical-sideeffects/hand-foot-syndrome-or-palmar-plantar-erythrodysesthe sia. Accessed 26 Feb 2020.

111. Chen M, Zhang L, Wang Q, Shen J. Pyridoxine for prevention of hand-foot syndrome caused by chemotherapy: a systematic review. PLoS One. 2013;8(8):e72245. https://doi.org/10.1371/ journal.pone.0072245.
112. Drui D, Illouz F, Do Cao C, Caron P. Expert opinion on thyroid complications of new anti-cancer therapies: tyrosine kinase inhibitors. Ann Endocrinol (Paris). 2018;79(5):569-73. https:// doi.org/10.1016/j.ando.2018.07.003.

113. Gerendash BS, Creel PA. Practical management of adverse events associated with cabozantinib treatment in patients with renalcell carcinoma. Onco Targets Ther. 2017;10:5053-64. https:// doi.org/10.2147/ott.s145295.

114. Institute of Medicine of the National Academies. Dietary reference intakes for water, potassium, sodium, chloride, and sulfate. Washington, DC: The National Academies Press; 2004.

115. Bolondi L, Craxi A, Trevisani F, Daniele B, Di Costanzo GG, Fagiuoli S, et al. Refining sorafenib therapy: lessons from clinical practice. Future Oncol. 2015;11(3):449-65. https://doi. org/10.2217/fon.14.261.

116. Johnson \& Johnson Consumer Inc. Imodium capsules Rx. 2016. https://www.accessdata.fda.gov/drugsatfda_docs/label /2016/017694s052lbl.pdf.

117. Cancer Treatment Centers of America. Loss of Appetite. 2019. www.cancercenter.com/integrative-care/loss-of-appetite. Accessed 16 July 2019.

118. Underhill ML, Ward VA. Cancer anorexia-cachexia syndrome. In: Brown CG, editor. A guide to oncology symptom management. Pittsburgh: Oncology Nursing Society; 2015.

119. Walsh D, Kirkova J, Davis MP. The efficacy and tolerability of long-term use of dronabinol in cancer-related anorexia: a case series. J Pain Symptom Manag. 2005;30(6):493-5. https://doi. org/10.1016/j.jpainsymman.2005.11.007.

120. Stricker CT, Wesmiller SW. Chemotherapy-induced nausea and vomiting. In: Brown CG, editor. A guide to oncology symptom management. Pittsburgh: Oncology Nursing Society; 2015.

121. Moffett PM, Cartwright L, Grossart EA, O'Keefe D, Kang CS. Intravenous ondansetron and the QT interval in adult emergency department patients: an observational study. Acad Emerg Med. 2016;23(1):102-5. https://doi.org/10.1111/acem.12836.

122. Brown CG. Mucositis. In: Brown CG, editor. A guide to oncology symptom management. Pittsburgh: Oncology Nursing Society; 2015.

123. Brown C. A guide to oncology symptom management. In: Brown C, editor. A guide to oncology symptom management. 2nd ed. Pittsburgh: Oncology Nursing Society; 2015.

124. Lalla RV, Bowen J, Barasch A, Elting L, Epstein J, Keefe DM, et al. MASCC/ISOO clinical practice guidelines for the management of mucositis secondary to cancer therapy. Cancer. 2014;120(10):1453-61. https://doi.org/10.1002/cncr.28592.

125. Oncology Nursing Society. Mucositis. 2017. www.ons.org/pep/ mucositis. Accessed 18 July 2019.

126. O'Leary C. Neutropenia and infection. In: Brown CG, editor. A guide to oncology symptom management. Pittsburgh: Oncology Nursing Society; 2015.

127. Lenihan DJ, Kowey PR. Overview and management of cardiac adverse events associated with tyrosine kinase inhibitors. Oncologist. 2013;18(8):900-8. https://doi.org/10.1634/theon cologist.2012-0466.

128. Larochelle P, Kollmannsberger C, Feldman RD, Schiffrin EL, Poirier L, Patenaude F, et al. Hypertension management in patients with renal cell cancer treated with anti-angiogenic agents. Curr Oncol. 2012;19(4):202-8. https://doi.org/10.3747/ co.19.972. 